which, with the marginal selenium availability in Finland, often fails in twin pregnancy. The possibility that increased metabolism of selenium, similar to that seen in the liver disease caused by valproic acid, ${ }^{22}$ or malabsorption due to cholestasis, ${ }^{23}$ might be responsible for the low serum concentrations of selenium in patients with this disease seems unlikely as the selenium concentrations were already low when the disease first manifested.

This study provides indirect evidence that the capacity of the liver to metabolise the products of hepatic oxidation - that is, the hepatic antioxidative defence mechanism - of oestrogens in patients with intrahepatic cholestasis of pregnancy may be impaired. This may lead to structural and functional damage to the hepatocytes, resulting in cholestasis.

We thank Miss Kaija Aura for her skilful technical help.

\section{References}

1 Kern F Jr, Erfling W, Simon FR, et al. Effect of estrogens on the liver. Gastroenterology 1978;75:512-22.

2 Schreiber AJ, Simon FR. Estrogen induced cholestasis: clues to pathogenesis and treatment. Hepatology 1983;3:607-13.

3 Agostini A, Gerli GC, Beretta L, et al. Erythrocyte antioxidant enzymes and selenium serum levels in an Andean population. Clin Chim Acta 1983;133:153-7.

4 Schwarz K. Essentiality and metabolic functions of selenium. Med Clin North Am 1976;60:745-58.

5 Muth OH, Weswig PH, Whanger PD, Oldfield JE. Effect of feeding selenium-deficient ration to the subhuman primate (Saimiri sciureus). Am $\mathcal{f}$ Vet Res 1971;32:1603-5.

6 Korpela H, Kumpulainen J, Luoma PV, Arranto AJ, Sotaniemi EA. Decreased serum selenium in alcoholics as related to liver structure and function. Am $\mathcal{F} \mathrm{Clin} N u t r$ 1985;42:147-51.

7 Mutanen M, Koivistoinen P. The role of imported grain on the selenium intake of Finnish population in 1941-1981. Int 7 Vitam Nutr Res 1983;53:102-8.
8 Scherlock S. Patterns of hepatocyte injury in man. Lancet 1982;i:782-6.

9 Dormandy TL. Free radical oxidation and antioxidants. Lancet 1978;i:647-50.

10 Slater TF. Free-radical mechanisms in tissue injury. Biochem $\mathcal{f}$ 1984;222:1-15. 10 Slater TF. Free-radical mechanisms in tissue injury. Biochem $\mathcal{f}$ 1984;222:1-15.

12 Ursini F, Maiorino M, Gregolin C. The selenoenzyme phospholipid hydroperoxide $C$ glutathione peroxidase. Biochim Biophys Acta 1985;839:62-70

13 Sies H, Graf P, Cadenas E. Hydroperoxide reduction in liver cells: calcium release and $\widehat{\Omega}$ relationship to arachidonate metabolism. In: Braquet $P$, Gavay RP, Frölich JC, Nicosia $S$, eds. Prostaglandins and membrane ion transport. New York: Raven Press, 1985:119-28. 각. 14 Burk RF, Masters BSS. Some effects of selenium deficiency on the hepatic microsomal $\mathbb{D}$ cytochrome P-450 system in the rat. Arch Biochem Biophys 1975;170:124-31.

15 Marks F, Hecker E. Metabolism and mechanism of action of oestrogens. XII. Structure TI and mechanism of formation of water-soluble and protein-bound metabolites of $\varrho$ oestrogens in rat liver microsomes in vitro and in vivo. Biochim Biophys Acta 1969;187:250-65.

16 Nelson SD, Mitchell JR, Dybing E, Sasame HA. Cytochrome P-450-mediated oxidation $\stackrel{\mathscr{C}}{\rightarrow}$ of 2-hydroxyestrogens to reactive intermediates. Biochem Biophys Res Commun 1976;70:음 1157-65.

17 Akerboom TPM, Bilzer M, Sies $H$. Relation between glutathione redox changes and $\overline{\bar{N}}$ biliary excretion of taurocholate in perfused rat liver. $\mathcal{F}$ Biol Chem 1984;259:5838-43.

18 Phillips MM, Oda M, Mak E, Fisher MM, Jeejeebhoy KN. Microfilament dysfunction as $\overparen{\mathbb{D}}$ a possible cause of intrahepatic cholestasis. Gastroenterology 1975;69:48-58.

19 Smith MT, Thor H, Jewell SA, Bellomo G. Sandy MS, Orrenius S. Free radical induced changes in the surface morphology of isolated hepatocytes. In: Armstrong D, Sohal RS, Gutlwe RG, Slater TF, eds. Free radicals in molecular biology, aging, and disease. $\vec{O}$ New York: Raven Press, 1984: 103-18.

20 Butler JA, Whanger PD, Tripp MM. Blood selenium and glutathione peroxidase activity $\overrightarrow{\vec{\omega}}$ in pregnant women. Comparative assays in primates and other animals. Am $\mathcal{F}$ Clin Nutr 1982;32:15-23.

21 Kauppila A, Jouppila P, Ylikorkala O, Koivisto M, Moilanen I. Twin pregnancy: $\frac{O}{3}$ a clinical study of 335 patients. Acta Obstet Gynecol Scand [suppl] 1975;44:5-12.

22 Hyrd RW, Van Rinsvelt HA, Wilder BJ, Meanhaut W, De Reu. L. Selenium, zinc, and copper changes with valproic acid: possible relation to drug side effects. Neuralogy 1984;34:1983-5.

23 Ward KP, Arthur JR, Russell G, Aggett PJ. Blood selenium content and glutathione of peroxidase activity in children with cystic fibrosis, coeliac disease, asthma, and epilepsy. of Eur 7 Pediatr 1984;142:21-4.

\title{
Relation between phenotype and banal melanocytic naevi
}

\author{
J S C ENGLISH, A J SWERDLOW, R M MACKIE, C J O'DOHERTY, J A A HUNTER, \\ J CLARK, D J HOLE
}

\begin{abstract}
In a study of risk factors for the development of melanocytic naevi in relation to the pathogenesis of malignant melanoma 197 white adults were examined by four dermatologists and naevus counts correlated with several other features. Highly significant associations were found between large numbers of banal acquired melanocytic naevi and the ability to tan easily without burning (skin types 3 and 4; relative risk 4.6), brown or hazel eyes (relative risk 3.5), green or grey eyes (relative risk 3.5), and brown or black hair (relative risk 3.7). No significant associations with numbers
\end{abstract}

\section{University of Glasgow}

J S C ENGLISH, MB, MRCP, registrar, department of dermatology

A J SWERDLOW, PHD, MFCM, senior lecturer, department of community medicine

R M MACKIE, FRSE, FRCPATH, professor, department of dermatology

J CLARK, BSC, research assistant, department of community medicine

Department of Dermatology, University of Edinburgh

C J O'DOHERTY, MSC, MRCP, lecturer

J A A HUNTER, MD, FRCPED, professor

West of Scotland Cancer Surveillance Unit, Glasgow

D J HOLE, MSC, senior statistician

Correspondence to: Professor R M MacKie, Department of Dermatology, University of Glasgow, Glasgow G12. of naevi were shown for parity or use of oral contraceptives or other steroid hormones.

This is the first study to find any relation between melanocytic naevi and phenotypic factors in a white population.

\section{Introduction}

Interest in the possible relation between melanocytic naevi and $\mathrm{O}$ malignant melanoma was stimulated by the description by Elder $N$ and colleagues of the so called "dysplastic naevus syndrome." $\sigma$ Recent studies have shown that large numbers of "banal" acquired $\frac{7}{0}$ naevi are a strong risk factor for melanoma. ${ }^{2.4}$ The magnitude of this risk is much greater than for any other risk factor so far established, $\mathrm{N}$ and thus the aetiology and epidemiology of naevi are currently $\omega$ important topics of investigation. There is at present very little published information on factors leading to the development ofe naevi.

Several studies have been reported of numbers of naevi in the $\stackrel{?}{+}$ newborn ${ }^{5-7}$ and in children and adults. ${ }^{7-11}$ These show that naevi are $\frac{0}{0}$ rarely present at birth, increase in number at puberty, and are much $\stackrel{\vec{\Phi}}{\vec{\Phi}}$ less numerous in subjects over 40 . The increase in the number of $\stackrel{?}{\overparen{P}}$ naevi at around puberty suggests that hormonal factors may be $\varrho$ important. The existence of chloasma, increase in pigmentation, and darkening of naevi during pregnancy ${ }^{12}$ and the detection of $\varnothing$ oestrogen and progesterone receptors on naevi ${ }^{13}$ also suggest a음 relation between naevi and hormonal stimulation. One study reported that systemic administration of corticotrophin and corti- 
sone resulted in hyperpigmentation and the development of new junctional naevi in five out of 31 patients. ${ }^{14}$

Several studies have compared numbers of naevi in different races, ${ }^{15-18}$ and one examined naevus counts in relation to tanning ability. ${ }^{19}$ Whole body naevus counts were performed in only one study, which compared naevus counts among racial groups. ${ }^{16}$ The highest counts were found in mestizos of mixed white and Indian blood. The average number of naevi in this group was twice that found in white American males. ${ }^{7}$

In this paper we report a study of various phenotypic and hormonal factors in relation to whole body naevus counts in a white population.

\section{Subjects and methods}

The subjects of our analysis were the control group-that is, patients without melanoma-from a case-control study of various possible risk factors for melanoma. ${ }^{4}$ The subjects consisted of 197 patients ( 120 female, 77 male) with a wide range of admission diagnoses, the most common being hypertension (55 patients), psoriasis (31), and fractures and dislocations (20); $134(68 \%)$ of the patients were interviewed and examined in Glasgow and $63(32 \%)$ in Edinburgh. Table I shows their age distribution.

Data on a wide range of phenotypic and environmental factors were obtained by interview and physical examination by trained dermatologists. The interview included questions on original hair colour, skin type-that is, tanning ability, as defined by the North American Co-operative PUVA Trial $^{20}$-obstetric history, and use of oral contraceptives and other systemic steroids. The physical examination included an assessment of eye colour and a count and examination of all pigmented lesions greater than $2 \mathrm{~mm}$ diameter considered to be melanocytic naevi on all body sites except the scalp and genitals. Clinical criteria for including a lesion as a melanocytic naevus were that it was a brown lesion on the skin which was not obviously a freckle, lentigo, or seborrhoeic wart.

Since naevus counts vary with age and $\operatorname{sex}^{8}{ }^{10}$ these variables had to be taken into account when deciding whether each subject had many or few naevi. The patients were therefore stratified by sex and 10 year age group and within each stratum ranked on the basis of their naevus counts and divided into tertiles-that is, lowest one third of naevus counts for that age and sex, middle one third, and highest one third. An overall group of patients with low counts was then assembled by totalling the patients from the low tertile of each stratum. Overall groups with medium and high numbers of naevi for their age and sex were similarly assembled. When several people in a stratum had the same number of naevi they were all allocated to the same tertile; thus, for instance, when several people in a stratum had no naevi all were included in the "low tertile," even when this resulted in over one third of patients in the stratum being allocated to that tertile.

Relative risks for phenotypic and hormonal factors in the medium and high compared with the low count groups were estimated by logistic regression analysis ${ }^{21} ; \chi^{2}$ linear trend was calculated to test the significance of gradients of risk among the low, medium, and high count groups. ${ }^{22}$

\section{Results}

\section{SKIN TYPE AND EYE AND HAIR COLOUR}

Significantly raised risks for medium and high numbers of naevi were found for subjects with skin types 3 (tans well and rarely burns) and 4 (always tans) compared with those with skin types 1 (never tans, always burns) and 2 (burns first but tans eventually) (table II). Indeed, there was a highly significant trend $(p<0.001)$ from the low to the high naevus count groups in the proportion of subjects with skin types 3 and 4

Raised risks for people with green or grey and brown or hazel eyes compared with those with blue eyes were found in the medium and high naevus count groups. Risks were significantly increased in the high naevus count group (table II). The trend in the proportion of non-blue-eyed subjects was highly significant $(p<0.001)$ among the low, medium, and high naevus count groups.

Significantly raised risks of medium and high naevus count were found for subjects with brown or black hair (table II), and the trend in the proportion with brown or black hair was significant $(p<0.01)$.

When the analyses for each of the above risk factors were repeated with adjustment for the other two factors-for example, risks by skin type adjusted for hair and eye colour-all of the relative risks decreased slightly; nevertheless, substantial gradients of risk remained for each variable. In analyses excluding the 77 subjects who had presented with dermatological conditions significant gradients of risk remained for skin type, eye colour, and hair colour, both in adjusted and in unadjusted analyses. The relative risks for high numbers of naevi were all greater than had been found in the analyses including the dermatological patients, while the risks for medium numbers of naevi altered less consistently (often based on small numbers).

\section{HORMONAL FACTORS AND SYSTEMIC CORTICOSTEROIDS}

No relation to numbers of naevi was found for ever or never use of oral contraceptives. Relative risks for ever users were $1 \cdot 1$ ( $95 \%$ confidence limits

TABLE I-Distribution of subjects by age group

\begin{tabular}{lccccccc}
\hline & \multicolumn{8}{c}{ Age group (years) } & \multirow{2}{*}{ Total } \\
\cline { 2 - 7 } & $15-$ & $25-$ & $35-$ & $45-$ & $55-$ & $\geqslant 65$ & No \\
\hline No (\%) of patients & $18(9)$ & $24(12)$ & $35(18)$ & $39(20)$ & $49(25)$ & $32(16)$ & $197(100)$ \\
\hline
\end{tabular}

TABLE II-Relative risks of medium and high naevus counts by skin type, eye colour, and hair colour

\begin{tabular}{|c|c|c|c|c|c|c|c|}
\hline \multirow[b]{2}{*}{ Risk factor } & \multicolumn{3}{|c|}{ No (\%) of patients with risk factor } & \multicolumn{2}{|c|}{$\begin{array}{l}\text { Relative risks ( } 95 \% \text { confidence interval) } \\
\text { compared with low naevus count group: } \\
\text { all subjects }\end{array}$} & \multicolumn{2}{|c|}{$\begin{array}{l}\text { Relative risks ( } 95 \% \text { confidence interval) } \\
\text { compared with low naevus count group: } \\
\text { excluding dermatological subjects }\end{array}$} \\
\hline & $\begin{array}{l}\text { Low naevus } \\
\text { count }\end{array}$ & $\begin{array}{l}\text { Medium naevus } \\
\text { count }\end{array}$ & $\begin{array}{l}\text { High naevus } \\
\text { count }\end{array}$ & $\begin{array}{l}\text { Medium naevus } \\
\text { count }\end{array}$ & $\begin{array}{c}\text { High naevus } \\
\text { count }\end{array}$ & $\begin{array}{l}\text { Medium naevus } \\
\text { count }\end{array}$ & $\begin{array}{l}\text { High naevus } \\
\text { count }\end{array}$ \\
\hline $\begin{array}{l}\text { Skin type: } \\
1,2 \\
3,4\end{array}$ & $\begin{array}{l}69(84) \\
13(16)\end{array}$ & $\begin{array}{ll}38 & (61) \\
24 & (39)\end{array}$ & $\begin{array}{ll}25 & (47) \\
28 & (53)\end{array}$ & $\begin{array}{l}1 \cdot 0 \\
3 \cdot 1(1 \cdot 2-8 \cdot 3)\end{array}$ & $\begin{array}{l}1 \cdot 0 \\
4 \cdot 6(1 \cdot 9-11 \cdot 3)\end{array}$ & $\begin{array}{l}1.0 \\
6.7(1.9-23 \cdot 2)\end{array}$ & $\begin{array}{l}1.0 \\
6.9(1 \cdot 9-25 \cdot 5)\end{array}$ \\
\hline $\begin{array}{l}\text { Eye colour } \\
\text { Blue } \\
\text { Green, grey } \\
\text { Brown, hazel }\end{array}$ & $\begin{array}{ll}58 & (71) \\
12 & (15) \\
12 & (15)\end{array}$ & $\begin{aligned} 38 & (64) \\
6 & (10) \\
15 & (25)\end{aligned}$ & $\begin{array}{ll}20(38) \\
15 & (29) \\
17 & (33)\end{array}$ & $\begin{array}{l}1 \cdot 0 \\
0 \cdot 9(0 \cdot 3-3 \cdot 1) \\
2 \cdot 5(0 \cdot 9-7 \cdot 2)\end{array}$ & $\begin{array}{l}1 \cdot 0 \\
3 \cdot 5(1 \cdot 3-9 \cdot 5) \\
3 \cdot 5(1 \cdot 3-9 \cdot 8)\end{array}$ & $\begin{array}{l}1 \cdot 0 \\
0 \cdot 8(0 \cdot 3-2 \cdot 7) \\
1 \cdot 3(0 \cdot 4-4 \cdot 7)\end{array}$ & $\begin{array}{l}1 \cdot 0 \\
5 \cdot 3(1 \cdot 2-22 \cdot 4) \\
5 \cdot 0(1 \cdot 2-21 \cdot 0)\end{array}$ \\
\hline $\begin{array}{l}\text { Hair colour at age 15: } \\
\text { Red, blond } \\
\text { Brown, black }\end{array}$ & $\begin{array}{ll}28 & (34) \\
54 & (66)\end{array}$ & $\begin{array}{l}10(16) \\
52(84)\end{array}$ & $\begin{aligned} 7 & (13) \\
46 & (87)\end{aligned}$ & $\begin{array}{l}1 \cdot 0 \\
2 \cdot 5(1 \cdot 0-6 \cdot 1)\end{array}$ & $\begin{array}{l}1 \cdot 0 \\
3 \cdot 7(1 \cdot 3-10 \cdot 1)\end{array}$ & $\begin{array}{l}1.0 \\
1.6(0.6-4.6)\end{array}$ & $\begin{array}{l}1 \cdot 0 \\
4 \cdot 0(1 \cdot 0-15 \cdot 6)\end{array}$ \\
\hline Total & $82(100)$ & $62(100)$ & $53(100)$ & & & & \\
\hline
\end{tabular}

*Excludes four subjects for whom eye colour not known.

$\chi_{1}^{2}$ Linear trend-Skin types $1,2 v$ not $1,2: 20.88(p<0.001)$ for all subjects; 8.94 ( $p<0.01$ ) excluding dermatological subjects. Blue eyes $v$ not blue eyes: 12.86 ( $\left.p<0.001\right)$ for all subjects; 6.12 $(p<0.2)$ excluding dermatological subjects. Red or blond hair 0 not red or blond hair: 8.97 (p<0.01) for all subjects; 5.38 (p<0.05) excluding dermatological subjects. 
0.4 and 3.2$)$ for medium naevus counts and $1.6(95 \%$ confidence limits 0.5 and 5.6 ) for high naevus counts. Naevus counts were also unrelated to the length of time for which the oral contraceptive had been taken, the age when the oral contraceptive was first started, and the year when it was first started. There was also no relation between naevus counts and various aspects of reproductive history, including age of menarche, age of menopause, whether ever or never pregnant, number of pregnancies, age of first pregnancy, sex of offspring, number of miscarriages, number of terminations, and number of stillbirths.

No raised risk was associated with use of systemic steroids, but the numbers of users were small.

\section{MISCELLANEOUS FACTORS}

There was no relation of numbers of naevi to various other factors, including dermatitis, vitiligo, chloasma, chronic fungal infections, recurrent herpes simplex, severe acne, psoriasis, and smoking, though these were often based on small numbers of positive responses. There was, however, a significant trend of risk $(p<0.05)$ for the presence of warts at age over 20 ; the relative risk for medium naevus counts was $1.3(95 \%$ confidence limits 0.3 and 6.4) and for high naevus counts $5 \cdot 1(95 \%$ confidence limits $0 \cdot 9$ and $30 \cdot 3)$.

\section{Discussion}

This study has identified a strong association between skin types 3 and 4 and high naevus counts and additional, largely independent associations for dark hair and non-blue eyes. The findings are analogous to the report by Pack et al that whole body naevus counts were higher in some darker skinned races (Filipinos, Chinese, and mestizo Indians) than in white Americans. ${ }^{16}$ Their paper, however, took no account of the age of the subjects, and no details of the consistency of naevus counting methods were given.

In another study naevi were found more frequently on the palms and soles of darker skinned people (Chinese, Latin Americans, and blacks) than of whites. ${ }^{17}$ The only other study giving data on the association of tanning ability in whites with prevalence of melanocytic naevi examined part of the arms only and did not allow for age and sex. ${ }^{19}$ It is therefore difficult to interpret the results of this study, which reported a higher proportion of people with average ability to tan than of those with low or deep tanning ability who had any naevi in the area examined.

As we considered that our results were unexpected, we reviewed numbers of naevi in relation to skin type in data from a study by MacKie et al. ${ }^{10}$ We found a similar gradient of risk by skin type: for example, in women aged 40-49 there was a clear trend to larger numbers of naevi in skin types 3 and 4 (average 37 naevi per person) compared with those with skin types 1 and 2 ( 9 naevi per person). We also counted naevi on the backs of 17 consecutive patients attending a contact dermatitis clinic. As before, significantly higher mean naevus counts were found in skin types 3 and 4 than in skin types 1 and 2.

The method of data collection in this study is unlikely to have led to bias. The data were not collected primarily for analysis of associations with naevi within the subjects but rather for a casecontrol study of risk factors for melanoma. ${ }^{4}$ In addition, the method of dividing subjects into low, medium, and high naevus count categories was not known to the dermatologists collecting the data. Indeed, the allocation of subjects to these groups could be made only retrospectively after data collection was complete. Gradients of risk with skin type, hair colour, and eye colour remained after exclusion of subjects who had presented with dermatological diagnoses, and we have no reason to believe that the other presenting diagnoses of subjects were related to numbers of naevi. Thus the results appear to be applicable to the general population for the range of phenotypes studied, though we emphasise that our study was confined to white people living in the west of Scotland.
We offer two possible explanations for the strong association w between skin types 3 and 4 and high naevus counts. Firstly, darker skinned people may have greater capacity to synthesise melanin, and therefore their naevi may be more apparent than those in fairer $c$ people. Secondly, manifestation of melanocytic naevi may be $\widehat{\widehat{O}}$ associated with exposure to the sun, ${ }^{2}{ }^{17}$ and since people with skin types 3 and 4 can tolerate the sun better than those with skin types 1 D and 2 they may expose themselves more to the sun and hence $\mathbb{D}$ develop more naevi.

There has been some evidence that pregnancy and oral contraception may be important in the aetiology of melanocytic naevi, ${ }^{12}$ but neither we nor a previous study ${ }^{10}$ found any association between high naevus counts and these hormonal factors.

In our study warts were a risk factor for high naevus counts. Possibly exposure to the sun reduces some aspects of cutaneous immunity and so might predispose to both warts and naevi. Alternatively, this may have been a chance finding. Further work is of required.

In the past few decades the incidence of and mortality from cutaneous malignant melanoma have been rising rapidly in white $\vec{\omega}$ populations around the world..$^{23}$ As large numbers of melanocytic naevi have been shown to be the strongest risk factor yet identified for malignant melanoma the aetiology and epidemiology of melano- is cytic naevi have assumed particular importance. We have found $\stackrel{\mathscr{\perp}}{\oplus}$ significant relations between high numbers of naevi and skin types $3 \dot{0}$ and 4, non-blue eyes, and brown or black hair.

We thank the Greater Glasgow Health Board Research Support Group $N$ and Eli Lilly and Company for financial help.

\section{References}

1 Elder DE, Goldman LI, Greene MH, Clark WH Jr. Dysplastic nevus syndrome: a phenotypic association of sporadic cutaneous melanoma. Cancer 1980;46:1787-94.

2 Holman CD, Armstrong BK. Pigmentary traits, ethnic origin, benign nevi, and family history as risk factors for cutaneous malignant melanoma. $7 N C I$ 1984;72:257-66.

3 Green A, MacLennan R, Siskind V. Common acquired naevi and the risk of malignant melanoma. Int $\mathcal{F}$ Cancer 1985;35:297-300.

4 Swerdlow AJ, English J, MacKie RM, et al. Benign melanocytic naevi as a risk factor for malignant melanoma. Br Med f 1986;292:1555-9.

5 Walton RG, Jacobs AH, Cox AJ. Pigmented lesions in newborn infants. $\mathrm{Br} \mathcal{I}$ Dermatol 1976;95:389-96.

6 Castilla EE, Da Graça Dutra M, Orioli-Parreiras IM. Epidemiology of congenital pigmented naevi: I. Incidence rates and relative frequencies. Brf Dermatol 1981;104:307-15.

7 Pack GT, Lenson N, Gerber DM. Regional distribution of moles and melanoma. Arch Surg 1952;65:862-70.

8 Nicholls EM. Genetic susceptibility and somatic mutation in the production of freckles, birthmarks, and moles. Lancet 1968 ;i:71-3.

9 Nicholls EM. Development and elimination of pigmented moles, and the anatomical distribution of primary malignant melanoma. Cancer 1973;32:191-5.

10 MacKie RM, English J, Aitchison TC, Fitzsimons CP, Wilson PD. The number and distribution of benign pigmented moles (melanocytic naevi) in a healthy British population. $\mathrm{Br} \mathcal{J}$ Dermato 1985;113:167-74.

11 Cooke KR, Spears GFS, Skegg DCG. Frequency of moles in a defined population. $\mathcal{F}$ Epidemio Community Health 1985;39:48-52.

12 Foucar E, Bentley TJ, Laube DW, et al. A histopathologic evaluation of nevocellular nevi in pregnancy. Arch Dermatol 1985;121:350-4.

13 Ellis DL, Wheeland RG. Increased nevus estrogen and progesterone ligand binding related to oral contraceptives or pregnancy. $f$ Am Acad Dermatol 1986;14:25-31.

14 Goldman L, Richfield DF. Effect of corticotropin and cortisone and progress of pigmented nevi.

JAMA 1952;147:941-3.
15 Cullen SI. Incidence of nevi. Arch Dermatol 1962;86:40-3.

16 Pack GT. Incidence of nevi. Arch Dermatol 1962;86:40-3. and melanomas. Ann NY Acad Sci 1963;100:719-42.

17 Allyn B, Kopf AW, Kahn M, Witten VH. Incidence of pigmented nevi. JAMA 1963;186:890-3. 18 Coleman WP, Gately LE, Krementz AB, Reed RJ, Krementz ET. Nevi, lentigines, and melanoma in blacks. Arch Dermatol 1980;116:548-51.

19 Kopf AW, Lazar M, Bart RS, Dubin N, Bromberg J. Prevalence of nevocytic nevi on lateral and medial aspects of arms. $\mathcal{F}$ Dermatol Surg Oncol 1978;4:153-8.

20 Melski JW, Tanenbaum L, Parrish JA, Fitzpatrick TB, Bleich HL. Oral methoxsalen photochemotherapy for the treatment of psoriasis: a co-operative clinical trial. I Invest Dermatol 1977;68:328-35.

21 Smith PG, Pike MC, Hill AP, Breslow NH, Day NE. Multivariate conditional logistic analysis of stratum-matched case-control studies. Applied Statistics 1981;30:190-7.

22 Rothman KJ, Boice JD Jr. Epidemiologic analysis with a programmable calculator. Bethesda, Md: Public Health Service, National Institutes of Health, 1979. (Monograph No 79-1649.)

23 Lee JAH. Melanoma and exposure to sunlight. Epidemiol Reo 1982;4:110-36.

(Accepted 12 November 1986) 